STICHTINGEN EN FONDSEN IN DE WEST

DOOR

FRED. OUDSCHANS DENTZ

II

Op Curaçao zelf bestaan nog de volgende fondsen:

1. The Hebrew Benevolent Society, in 1715 opgericht, waaruit in den loop der tijden is voortgesproten The Curaçao Ladies' Hebrew Benevolent Society, in 1866 op Curaçao opgericht.

2. De Alliance Israëlite Universelle, in 1860 te Parijs gesticht. Hiervan werd een plaatselijk comité op 2 September 1864 op Curaçao opgericht op aanstichting van nu wijlen de heeren B. de Sola en diens neef M. de Sola.

3. De Israëlietische Weldadigheidsvereeniging Alivio del „Pobre" welke op 22 October 1879 werd gesticht ten bate van in nood verkeerende Israëlieten, zoowel inheemsche als doortrekkende.

4. Op 30 Mei 1885 stichtte men op Curaçao het fonds Montefiore als aandenken aan Sir Mozes Montefiore, den bekenden philantroop die 8 November 1883100 jaar geleden geboren werd.

5. Als 5de fonds kan genoemd worden het Elias S. L. MaduroWeldadigheidsfonds dat den 3den October 1911 werd gesticht na het overlijden van genoemden heer Maduro. De beide laatstgenoemde fondsen staan open voor ieder, zonder onderscheid van geloof.

6. Armenzorg Fonds gesticht op 27 December 1917, onder contrôle van de Vrijmetselaarsloge „De Vergenoeging”, werkende onder het Groot Oosten van Nederland tot het bedeelen van thuis zittende armen, onverschillig van welke gezindte.

7. Bedelaarsfonds, opgericht 1 Juli 1917, onder contrôle van de Vrijmetselaarsloge „De Vergenoeging” ter bedeeling van bedelaars, ten einde het bedelen langs de huizen tot een minimum te beperken.

8. Fonds tot leniging van armoede onder contrôle van de Vrij-

West-Indische Gids XVI 
metselaarsloge „De Vergenoeging” met het doel om armen, onverschillig van welke gezindte, in tijden van dringenden nood hulp te verleenen.

9. Fonds Prins Frederik der Nederlanden onder contrôle van de Vrijmetselaarsloge „De Vergenoeging”. Ten doel hebbende studiebeurzen te verleenen aan Curaçaosche jongelieden, die niet in staat zijn hun studie te bekostigen. Eventueel ook voor studie elders dan in Curaçao.

10. Asistencia Mutua. Fonds onder controle van de loge Igualdad no. 653, werkende onder het Groot Oosten van Engeland. Het doel is hulp aan thuis zittende armen te verleenen, eventueel geneeskundige hulp en hospitaalverpleging aan minbedeelden.

11. Fondo Victoria (Victoria Fonds). Onder contrôle van de loge Igualdad no. 653. Ten doel hebbende het onderwijs in het algemeen in een vrijzinnige richting aan minvermogenden te bevorderen, door het contrôleeren van schoolbezoek, bekostigen van schoolgelden en het oprichten van lagere scholen. In 1933 richtte de vereeniging de Willem-de-Zwijgerschool op (Lagere school voor niet betalenden).

12. La Caridad. Fonds onder contrôle van de loge Perseverancia no. 184 werkende onder het Groot Oosten van Mark-Meesters van Engeland tot het verstrekken van hulp aan behoeftigen in het algemeen.

\section{BRITSCH GUYANA.}

Demerara, de schepping van Storm van 's Gravensande, dat eenige malen van eigenaar verwisselde voordat het in 1803 voor de derde maal en dan voor goed onder Engelsch bestuur kwam, was van 1784 tot 1796, evenals Essequebo en Berbice, weder Nederlandsch. Waarnemend Directeur-Generaal en Gouverneur was van Febr. tot Oct. 1784 Joseph Bourda (naar wien een der stadswijken thans in Georgetown heet). Onder zijn bestuur stierf in Augustus 1784 in Demerara Pierre Louis de Saffon, die in 1724 in Frankrijk was geboren. Hij kwam van Languedoc. Weinig is van zijn jeugd bekend. Alleen het volgende. Met zijn lievelingsbroeder toonde hij groote genegenheid voor dezelfde dame en dit leidde tot openlijke vijandschap en ten slotte tot een tweegevecht, waarin Pierre zijn broeder doodde. Hij vluchtte naar Demerara en vestigde zich als planter en kwam tot grooten rijkdom. Maar de wroeging knaagde, hetgeen wel bleek uit de namen welke hij zijn 
plantages heeft gegeven als: La Penitence, La Repentir, Mon Repos, en Regret. Ofschoon nimmer gehuwd, had hij volgens de gewoonten van zijn tijd een inlandsche huishoudster, Nanci, bij wie hij een dochter had, Lena. Nimmer zag hij zijn geboortegrond weer en toen hij overleed bleek uit zijn testament, dat hij een som van 20.000 gulden had nagelaten voor een fonds dat nu het Saffonfonds heet en dat de volgende bepaling inhield. Na eenige beschikkingen te hebben gemaakt verklaarde hij tot universeele erfgenamen tien kinderen, weezen en halfweezen, in de kolonie geboren uit wettig huwelijk, die bij overlijden eeuwigdurend door anderen zouden moeten worden vervangen. Hij machtigde den Hove van Justitie, wanneer het kennis kreeg van de executeurs, van het overlijden van een kind, in de vacature steeds een ander, en wel het armste, kind te kiezen, uit blanke ouders geboren, dat uit de fondsen zou worden opgevoed tot het zijn 16de jaar bereikt zou hebben, waarna het door een ander moest worden vervangen. Als eerste deelgenooten wees de erflater aan Annie Marie Gelot, Jeanne Catherine Gelot en Guilhaume Daniel Bellot met verzoek aan den Hove de overige 7 aan te wijzen. Tot executeurs en voogden wees hij de eerste maal de heeren Albinus en Chevalier de Cornette aan.

Nadat de bepalingen in het testament de eerste maal waren uitgevoerd, ging het fonds over in handen van den heer Anthony Meertens, die het op zijn beurt aan Charles Vincent overmaakte. Beide heeren deden evenwel niets om de laatste wilsbeschikking behoorlijk uit te voeren, totdat na jaren de redacteur van de Guiana Chronicle and Demerara Gazette er in Mei 1822 er de aandacht op vestigde. Het bestaan van het fonds was door twee geestelijken, leden van het armenfonds, ontdekt, die een behoorlijk onderzoek naar de administratie van het fonds wenschten, maar zij ondervonden zulk een vijandige houding en tegenwerking, dat zij, zwak genoeg, hun klachten introkken. De redacteur van voornoemde krant vreesde evenwel geen bedreiging en bracht de aangelegenheid in krachtige taal voor het publiek. Na deze actie is het testament behoorlijk uitgevoerd. Het fonds werd onder beheer van een zekere Mevrouw M. L. Vyfhuis geplaatst, die 19 jaren aan het hoofd van een meisjesschool had gestaan en het volle vertrouwen genoot. Toen de school in 1904 gesloten werd maakte het Hof van Policie van Britsch Guyana voorziening in de uitvoering van het testament, waaraan thans strikt de hand wordt gehouden.

Voor den erflater werd in de St. Saviour's kerk te Georgetown een gedenksteen opgericht waarop wij het volgende opschrift le- 
zen: „Pierre Louis de Saffon, born in France in the year 1724 dan died in Demerara in August 1784. The revenue of his estate after other bequests, he bestowed in perpetuity for the maintenance of ten poor destitute orphans until attaining the age of 16 years. The first orphan was educated at the Saffon school on the election of the Honourable the Supreme Court of Justice in the year 1825.

Hear, ye children, the instruction of a father, and attend to know understanding".

\section{VOOR BEIDE GEBIEDSDEELEN SURINAME EN CU- RAÇAO.}

a. Steunfonds voor Studeerenden uit West-Indië. Eenige belangstellenden in de bevolking van de Westindische gebiedsdeelen hebben den 5den September 1922 eene stichting onder dezen naam in het leven geroepen.

Het doel der stichting is:

$a$. de studie te bevorderen en te vergemakkelijken van personen, zonder onderscheid van kunne, afkomstig uit Suriname en Curaçao, die zich in Nederland tot eenigen werkkring bekwamen of aldaar hun opvoeding genieten.

$b$. zich te wijden aan het zedelijk welzijn der hierbedoelde personen.

Een rondzendbrief zette uiteen hoe men dat doel wilde trachten te bereiken en werd in de West-Indische Gids 4de jaargang 1922/3 5 de deel opgenomen (blz. 574/5).

De eerste maal werd het beheer der stichting opgedragen aan de heeren:

W. J. Cohen Stuart, oud-Minister van Marine, vert. der Ver. Oost en West, dr. B. de Gaay Fortman, Rechter in de Arr. Rechtbank te Dordrecht, S. van Lier Ez., Assuradeur te Amsterdam, G. J. Oudemans, oud-resident, Raadsman voor studeerenden van het Departement van Koloniën, mr. dr. C. F. Schoch, Hoofd-Directeur van de Surinaamsche Bank, G. J. Staal, oudgouverneur van Suriname en mr. dr. J. Versteeg, Secretaris van den Gem. Woningdienst te Amsterdam.

Secretaris is thans de heer C. K. Kesler, archivaris van de WestIndische Kamer, terwijl de heer Versteeg nog penningmeester is.

Voorschotten werden in den loop der jaren verleend aan 11 personen, t.w. 2 jongelieden die een zeevaart-examen deden, 2 hoogereburgerscholieren, 1 candidaat arts, 1 candidaat tandarts, 1 candidaat middelbaar akte teekenen, 1 leerling middelbare technische school en 1 meisje voor muziekonderwijs. 
Volgens mededeeling van den penningmeester worden de geleende gelden slecht terugbetaald. De beheerders hebben zich strikt gehouden aan de bedoeling slechts diegenen te steunen, die door onverwachte omstandigheden, (ontvallen van ouders of anderen die de studie bekostigden of ook niet toereikend blijken van voor studie opgespaarde gelden) hun studie niet zouden kunnen voortzetten.

b. Het Van-Eedenfonds. Toen de West-Indische tentoonstelling te Haarlem in 1899 was geëindigd, bleek er een bedrag van ongeveer $f 1000$ ongebruikt te zijn gebleven. Op 22 November 1899 richtte een commissie van negen heeren een rondschrijven aan de ingezetenen van Suriname, waarin zij voorstelde dit bedrag tot grondslag te doen strekken van een fonds, bestemd om de kosten te helpen bestrijden van het meestgeliefde denkbeeld van Frederik van Eeden: het floristisch onderzoek van Suriname, aan welk fonds men blijvend den naam wenschte te verbinden van dezen onvermoeiden strijder voor de belangen van Suriname en het te noemen Van-Eedenfonds. In een brief van 14 Februari 1901 schreef Van Eeden deze hulde dankbaar te willen aanvaarden en daarbij zelf nog $f 1000$ te voegen. In korten tijds bereikte het fonds een bedrag van $f 6.388,52$, welk bedrag aan Van Eedens opvolger, dr. M. Greshoff te Haarlem werd overgemaakt en dat onder toezicht van den Raad van Bestuur van het Koloniaal Museum door den directeur dier inrichting zou worden beheerd. Na Greshoffs dood in 1909 was het fonds $f 10.000$ groot en erfde het van dr. Greshoff nog $f 3.500$ bij. Later werd het fonds, dat door een commissie van drie leden werd beheerd, nog eens belangrijk versterkt door een schenking der Maatschappij van Nijverheid bij den overgang van het Koloniaal Museum aan het Koloniaal Instituut.

Nog is te vermelden, dat bij gouvernementsresolutie van 7 Maart 1902 een blijvende commissie in Suriname werd ingesteld. Het eerste verslag verscheen over 1902.

Als de middelen om het in art. 2 der statuten van het in 1913 opgerichte Van-Eedenfonds omschreven doel — bevordering van het botanisch onderzoek van Suriname, zoomede der West-Indische eilanden, bepaaldelijk van de studie der flora van die gewesten - te bereiken, zal de commissie voornamelijk beschouwen:

$a$. het verleenen eener subsidie aan een Nederlandsche plantkundige, die Suriname of de Nederlandsche West-Indische eilanden met het oogmerk van botanische floristische studiën wenscht te bezoeken. 
$b$. het verleenen eener subsidie aan een Nederlandsche plantkundige die ter plaatse of hier te lande studiën onderneemt, betreffende de flora van Ned. West-Indië.

$c$. het verleenen eener subsidie voor de uitgave van boek- en plaatwerken, deze flora betreffende.

$d$. het uitschrijven van prijsvragen, en de belooning van prijsvraagantwoorden, betreffende bedoelde flora of andere onderwerpen van botanischen aard, van belang voor Nederlandsch WestIndië.

e. het uitreiken van de Van-Eedenmedaille aan personen, die zich naar het inzicht der commissie bijzonder verdienstelijk hebben gemaakt ten aanzien van het botanisch onderzoek van Suriname en de West-Indische eilanden.

De jaarverslagen van het fonds verschijnen in het Jaarverslag van het Koloniaal Instituut en in de West-Indische Gids. Het 31 ste verslag is thans verschenen (over het jaar 1932). Het fonds was einde 1932 groot: $f 39.923,28^{1} / 2$.

Als bulletins van het Koloniaal Museum verschenen 2 publicatien van het Van-Eedenfonds (nos. 38 en 47 onderscheidelijk in 1907 en 1911). De 3de uitgave is de flora van de Westindische eilanden door dr. J. Boldingh, terwijl met de publicatie van The Flora of Surinam, onder redactie van prof. dr. A. Pulle een aanvang is gemaakt.

Ten slotte kan worden aangeteekend, dat in 1918 de statuten een wijziging hebben ondergaan bij akte onder dagteekening van 24 April. 